\title{
Factors associated with sub-microscopic placental malaria and its association with adverse pregnancy outcomes among HIV- negative women in Dar es Salaam, Tanzania: a cohort study
}

Aneth Vedastus Kalinjuma ${ }^{1,2^{*}}$ (D) Anne Marie Darling ${ }^{2}$, Ferdinand M. Mugusi ${ }^{3}$, Ajibola Ibraheem Abioye ${ }^{2}$, Fredros O. Okumu', Said Aboud ${ }^{3}$, Honorati Masanja', Davidson H. Hamer ${ }^{4,5}$, Ellen Hertzmark ${ }^{2}$ and Wafaie W. Fawzi ${ }^{2}$

\begin{abstract}
Background: Malaria infection during pregnancy has negative health consequences for both mothers and offspring. Sub-microscopic malaria infection during pregnancy is common in most African countries. We sought to identify factors associated with sub-microscopic placental malaria, and its association with adverse pregnancy outcomes among HIV-negative pregnant women in Dar es Salaam, Tanzania.

Methods: We recruited a cohort of pregnant women during their first trimester and assessed for the occurrence of placental malaria and pregnancy outcomes. The follow-up was done monthly from recruitment until delivery. Histopathology placental malaria positive results were defined as the presence of malaria pigment or parasitized erythrocytes on the slide (histology-positive (HP)), and the sub-microscopic placental infection was defined as positive Plasmodium falciparum DNA by polymerase chain reaction (DNA PCR) amplification in a negative histopathology test. Adverse pregnancy outcomes investigated included low birth weight (birth weight below $2.5 \mathrm{~kg}$ ), prematurity (live birth below 37 weeks), and small-for-gestational-age (SGA) (live born with a birth weight below 10th percentile for gestational age and sex). Weighted baseline category logit, log-binomial, and log-Poisson models were used to assess factors associated with placental malaria, and its association with adverse pregnancy outcomes.

\footnotetext{
* Correspondence: avedastus@gmail.com

${ }^{1}$ Department of Intervention and Clinical Trials, Ifakara Health Institute, P.O. Box 53, Ifakara, Morogoro, Tanzania

${ }^{2}$ Department of Global Health and Population, Harvard T.H. Chan School of Public Health, Boston, MA, USA

Full list of author information is available at the end of the article
}

C C The Author(s). 2020 Open Access This article is licensed under a Creative Commons Attribution 4.0 International License, which permits use, sharing, adaptation, distribution and reproduction in any medium or format, as long as you give appropriate credit to the original author(s) and the source, provide a link to the Creative Commons licence, and indicate if changes were made. The images or other third party material in this article are included in the article's Creative Commons licence, unless indicated otherwise in a credit line to the material. If material is not included in the article's Creative Commons licence and your intended use is not permitted by statutory regulation or exceeds the permitted use, you will need to obtain permission directly from the copyright holder. To view a copy of this licence, visit http://creativecommons.org/licenses/by/4.0/ The Creative Commons Public Domain Dedication waiver (http://creativecommons.org/publicdomain/zero/1.0/) applies to the data made available in this article, unless otherwise stated in a credit line to the data. 
(Continued from previous page)

Results: Among 1115 women who had histopathology and DNA PCR performed, 93 (8\%) had HP placental infection, and 136 (12\%) had the sub-microscopic placental infection. The risk of sub-microscopic placental malaria was greater in women who did not use mosquito prevention methods such as bed nets, fumigation, or mosquito coils (odds ratio $(O R)=1.75 ; 95 \%$ confidence interval $(C l): 1.05-2.92 ; P=0.03)$ and in women who were anemic $(O R=1.59 ; 95 \% \mathrm{Cl}: 1.20-$ $2.11 ; P=0.001)$. Women who were underweight had reduced odds of sub-microscopic placental malaria infection $(\mathrm{OR}=$ 0.33; 95\% Cl: 0.17-0.62; P = 0.001). Women who were overweight/obese had 1.48 times higher the odds of HP placental malaria compared to normal weight $(\mathrm{OR}=1.48 ; 95 \% \mathrm{Cl}: 1.03-2.11 ; P=0.03)$. HP placental malaria infection was associated with an increased risk of SGA births ( $R R=1.30,95 \% \mathrm{Cl}: 0.98-1.72, P=0.07)$. In contrast, the sub-microscopic infection was associated with a reduced risk of SGA births ( $R R=0.61,95 \% \mathrm{Cl}: 0.43-0.88, P=0.01)$. Placental malaria was not associated with low birth weight or prematurity.

Conclusion: Malaria prevention methods and maternal nutrition status during early pregnancy were important predictors of sub-microscopic placental malaria. More research is needed to understand sub-microscopic placental malaria and the possible mechanisms mediating the association between placental malaria and SGA.

Keywords: Sub-microscopic parasitemia, placental malaria, low birth weight, Premature, Small for gestational age, Histopathology, DNA PCR

\section{Background}

Worldwide, 75,000 to 200,000 infant deaths every year are attributable to malaria infection during pregnancy (MiP) [1]. Approximately 25 million pregnant women are at risk of Plasmodium falciparum (P. falciparum) infections each year in sub-Saharan Africa [2]. Twenty-six percent of severe anemia during pregnancy is attributable to MiP, and the proportion of maternal deaths linked to malaria infections ranges from 0.5 to $23 \%$ in hospital-based studies and 3 to $18 \%$ in community-based studies $[1,2]$. MiP also increases the risk of various adverse pregnancy outcomes such as low birth weight (LBW), prematurity, intrauterine growth retardation (IUGR), and stillbirth [1-3]. Further, the offspring of mothers diagnosed with placental malaria also have an increased risk of all-cause anemia and malaria infection during infancy $[4,5]$.

Histopathology examination of stained placental biopsies is considered as the gold standard for diagnosis of placental malaria (hereafter referred to as histologypositive (HP) placental malaria), but this test is impractical or not available in some settings $[6,7]$. Previous studies have pointed out that pregnant women often have low parasite densities, and the use of highly sensitive diagnostic methods such a DNA polymerase chain reaction (DNA PCR) (referred to as sub-microscopic placental malaria) has been recommended to enhance detection of placental malaria [6]. Sub-microscopic MiP remains common in most African countries including Tanzania [8-11], even though there was a $41 \%$ reduction of the malaria incidence rate in sub-Saharan Africa for the period of 2000-2015 [12]. The decreasing proportion of individuals presenting with clinical malaria infection over time has been linked with the scale-up of effective malaria interventions including insecticide- treated nets, effective case management, and indoor residual spraying [13].

Peripheral sub-microscopic malaria is strongly associated with placental malaria and low maternal hemoglobin levels $[14,15]$, but there are contradictory findings about the association between placental malaria and adverse pregnancy outcomes [11, 16, 17]. Cottrell et al. [16] found that sub-microscopic malaria infection during early pregnancy was associated with adverse pregnancy outcomes, whereas infection detected at delivery in the placenta and peripheral blood sample was not. In contrast, Cohee et al. [14] did not find an association between adverse pregnancy outcomes and peripheral sub-microscopic infection detected during pregnancy, and at delivery, and submicroscopic placental malaria. As a result, the WHO has recommended more studies to investigate the association between sub-microscopic infection and adverse pregnancy outcomes [18].

Limited evidence is available on the association between adverse pregnancy outcomes and placental malaria infections (particularly sub-microscopic variant) in tropical African cities such as Dar-es-Salaam, Tanzania, where the malaria burden has been significantly reduced, but low-level transmission remains. We, therefore designed a study with the objectives of identifying factors associated with sub-microscopic placental malaria and examined its association with LBW, prematurity, and small-for-gestational-age (SGA) births among HIVnegative pregnant women in their first and second pregnancy in Dar Es Salaam, Tanzania.

\section{Methods}

\section{Study design and participants}

We used data from a trial that examined the effect of prenatal vitamin A and zinc supplements on malaria in 
pregnancy among women in their first or second pregnancy [19]. In brief, women were randomized to placebo (625 women), vitamin A alone (625 women), zinc alone (625 women), and vitamin A and zinc (625 women). Women were enrolled in their first trimester (below 13 weeks of gestation) and followed up monthly until delivery for placental malaria and adverse pregnancy outcomes. Gestational age was estimated using the last menstrual period. Recruitment occurred between December 2010 and September 2013, and follow-up ended in June 2014. Trial recruitment sites were in Ilala and Temeke districts, Dar-es-Salaam, Tanzania. All women included in the trial received iron (60 mg daily) and folic acid (5 mg daily) supplements, a voucher for insecticidetreated bed nets, and sulphadoxine-pyrimethamine (SP) (1500 $\mathrm{mg}$ sulfadoxine and $75 \mathrm{mg}$ pyrimethamine) as per Tanzanian standard of care.

Socio-demographic and clinical variables were assessed at recruitment (baseline); these include age, parity, twin pregnancy status, years of education, marital status, gestational age, employment status, and use of fumigation, mosquito coil or bed nets at night. Selected possessions were asked about, from which a Filmer-Pritchet wealth index was computed [20]. Body mass index (BMI) (weight in kg divided by height (in meters) squared) and hemoglobin (in $\mathrm{g} / \mathrm{dL}$ ) were assessed. Age was classified into $\leq 24,25-34$ and $\geq 35$ years, and years of education were categorized into 0-7 (no education to primary school education), 8-11 (secondary school education), and $\geq 12$ years (high school and above education). The wealth index was grouped into quartiles, BMI was classified as $<18.5$ (underweight), 18.5-24.9 (normal weight) or $\geq 25 \mathrm{~kg} / \mathrm{m}^{2}$ (overweight/obese) [21], and hemoglobin was classified as $\geq 11.0 \mathrm{~g} / \mathrm{dL}$ (not anemic) or $<11.0 \mathrm{~g} / \mathrm{dL}$ (anemic) [22].

\section{Outcomes assessed at delivery}

Placental malaria was evaluated using both histopathology and DNA PCR. HP placental malaria was defined as the presence of malaria pigment or parasitized erythrocytes on the slide, and sub-microscopic placental malaria infection was defined as positive P. falciparum DNA by PCR amplification in samples negative for histopathology test. Details on the two methods have been previously described [19]. Briefly, tissue from fresh sampled placentas was collected during delivery and the collected sample was divided for both uses. Histopathologic infections were defined as the presence of malaria pigment or parasitized erythrocytes on tissue from a central parenchymal section of the placenta. Placenta samples were stained and then examined using polarized light microscopy. A single placental histopathologist classified all slides, and quality control of diagnoses were done externally in a subset of 100 slides.
For the nucleic acid studies, tissue was stabilized in RNA later (Qiagen, Hilden, Germany) and homogenized. Genomic DNA was extracted using DNeasy (Qiagen). Taqman $^{\circ}$ qRT-PCR (Thermo Fisher Scientific, Waltham, MA) was used for amplification using published primer and probe sets ( $P$. falciparum-specific [23] and general Plasmodium 18S rRNA genes [24]). The tissue was then tested for PCR inhibitors. Positive and negative controls were included on each plate for quality, and the minimum parasite density detection level was 0.000362 parasites/ $\mu \mathrm{L}$ [24]. At recruitment and during follow-up peripheral malaria infection was diagnosed using microscopy of thin and thick Giemsa staining blood smears.

Adverse pregnancy outcomes investigated in this study were LBW (birth weight below $2.5 \mathrm{~kg}$ ), SGA births (live birth weight below $10^{\text {th }}$ percentile for the exact day of gestation and sex based on INTERGROWTH-21 ${ }^{\text {st }}$ standards $[25,26])$ as a proxy outcome of IUGR, and prematurity (live birth before 37 weeks of gestation).

\section{Statistical analysis \\ Factors associated with placental malaria infection at delivery}

Baseline continuous variables were presented as medians and their interquartile ranges (IQR) and categorical variables as numbers and their percentage. To assess factors associated with placental malaria, baseline category logit regression models were used. Since we were unable to obtain placental samples for over $40 \%$ of women recruited for the original study due to changes in delivery plans, we weighted observations to account for nonresponse bias by the inverse of the probability of women having placental samples (for both tests) as determined by a multivariable logistic regression model [27]. In building the multivariable models, variables were selected based on univariable analysis. Variables with $p$ values less than 0.2 were considered potential variables for the multivariable models (these included employment, gestational age at baseline, and BMI). Other covariates were included based on prior knowledge of the topic (years of education, wealth index, gravidity, mosquito prevention methods, anemia status). Due to the positive correlation between maternal age and parity in this population ( $\rho=0.3$ with $P<0.0001$ ) maternal age was not included in any multivariable models. The trial regimens were forced into the multivariable models. Lastly, results were presented as odds ratio (OR) and their $95 \%$ confidence intervals.

\section{The association between placental malaria and adverse pregnancy outcomes}

In each outcome, the distributions of outcomes by exposure were presented in numbers and their percentage. To investigate the relationship of placental malaria with 
LBW, premature birth, and SGA birth, weighted logbinomial models, and log-Poisson models (with weights obtained from logistic regression models as described above) were used, [27, 28]. For HP placental malaria, the logistic regression model used to estimate the probabilities for weights was not stable due to a few cases in one of the age categories. In this case, we used the Firth penalized maximum likelihood estimation method [29]. All models were adjusted for employment status, years of education, wealth quartiles, trial regimen, gravidity, use of malaria interventions, twin pregnancy status, BMI, and anemia status at baseline. Results were presented using relative risk (RR) and their 95\% confidence intervals.

Analyses were performed among women with both tests done. In this case, placental diagnoses were classified as HP placental malaria, sub-microscopic positive placental malaria when histopathology was negative, and negative for both diagnoses. The level of significance was 0.05 , and all data analyses were conducted in SAS version 9.4 (SAS Institute Inc., Cary, NC, USA).

\section{Results}

The original trial recruited 2500 pregnant women in their first trimester (Fig. 1). Of these 2434 had known birth outcomes and among those with known birth outcomes, we excluded 1030 women due to missing placentas. Among women with placenta samples, 1115 (79\%) women had samples for both histology and PCR, 246 had samples only for histology and 43 had samples only for DNA PCR. Baseline characteristics in the groups of women with and without placenta samples were similar (Table 1). Among women included in the analysis, at baseline, the median age was 22 years with IQR [20-25] and the median gestational age was 10 weeks with IQR [8-12] (Table 2). Further, the majority were unemployed (53\%), married or cohabiting (90\%), with $0-7$ years of education level (72\%). Almost all women had singleton pregnancies (98\%) and 93\% used either fumigation or mosquito coils or bed nets at night. Underweight and peripheral malaria was less frequent (11 and $2 \%$ respectively), while anemia was very common (29\%).

Among 1404 women, there were 1115 (79\%) pregnant women with sufficient placenta samples for both diagnostic methods, $886(80 \%)$ tested negative by both methods, 93 (8\%) had HP placental malaria, and 136 (12\%) had sub-microscopic placental malaria.

\section{Factors associated with placental malaria infection at delivery}

The distribution of baseline characteristics was presented in Table 2. According to both diagnostic methods, participants with placental malaria were more frequently unemployed (59\% for DNA PCR and 65\% for histopathology versus $51 \%$ for negative results), less educated $(78 \%$ for DNA PCR and $76 \%$ for histopathology versus $71 \%$ for negative results), and anemic (33\% for DNA PCR and 36\% for histopathology versus $28 \%$ for

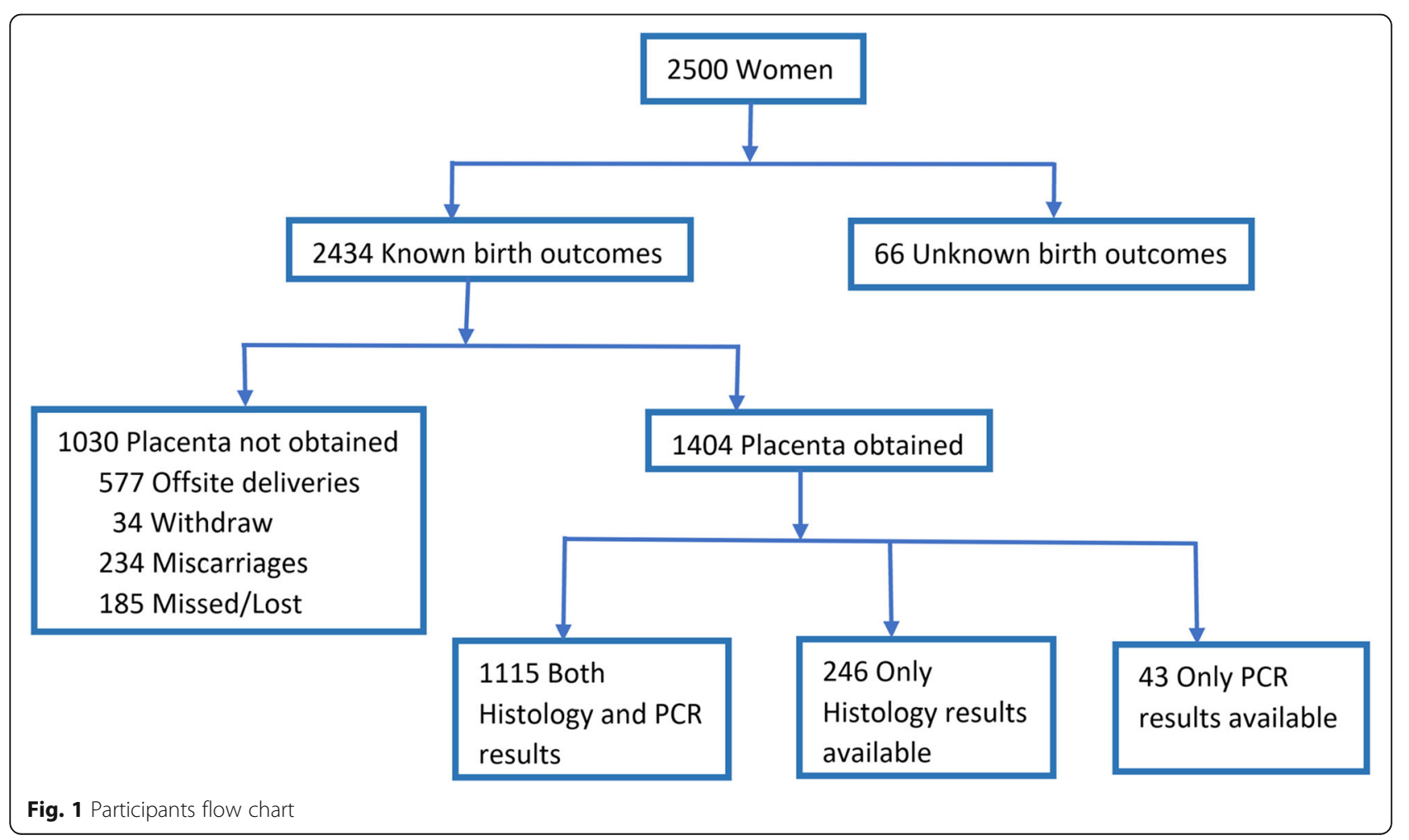


Table 1 The distribution of baseline characteristics among pregnant women with and without placenta sample for placental malaria diagnosis, 2010-2014 Dar-es-Salaam, Tanzania

\begin{tabular}{|c|c|c|}
\hline \multirow[t]{2}{*}{ Characteristics } & \multicolumn{2}{|c|}{ Placenta sample } \\
\hline & No $(n=1096)^{\mathrm{a}}$ & Yes $(n=1404)$ \\
\hline Maternal age in years, median (IQR) & $22(20-25)$ & $22(20-25)$ \\
\hline \multicolumn{3}{|l|}{ Maternal age in years, $\mathrm{n}(\%)$} \\
\hline 24 and below & $815(74.7)$ & $993(71.0)$ \\
\hline $25-34$ & $268(24.6)$ & $388(27.7)$ \\
\hline 35 and above & $8(0.7)$ & $18(1.3)$ \\
\hline Gestational age in weeks ${ }^{\mathrm{b}}$, median (IQR) & $10(8-12)$ & $10(8-12)$ \\
\hline \multicolumn{3}{|l|}{ Employment, n (\%) } \\
\hline Employed $^{c}$ & $326(29.9)$ & $415(29.9)$ \\
\hline Unemployed & $620(56.9)$ & $764(54.9)$ \\
\hline Other & $144(13.2)$ & $214(15.4)$ \\
\hline \multicolumn{3}{|l|}{ Marital status, n (\%) } \\
\hline Living single $^{d}$ & $100(9.2)$ & $141(10.1)$ \\
\hline Married or cohabitating & $989(90.8)$ & $1255(89.9)$ \\
\hline \multicolumn{3}{|l|}{ Years of education, $n(\%)$} \\
\hline $0-7$ & $774(70.7)$ & $1013(72.2)$ \\
\hline $8-11$ & $270(24.7)$ & $316(22.5)$ \\
\hline 12 and above & $51(4.7)$ & $75(5.3)$ \\
\hline \multicolumn{3}{|l|}{ Wealth quartile, n (\%) } \\
\hline 1 (Lowest) & $243(23.7)$ & $347(26.4)$ \\
\hline 2 & $259(25.3)$ & $306(23.3)$ \\
\hline 3 & $317(30.9)$ & $402(30.6)$ \\
\hline 4 (Highest) & $206(20.1)$ & $261(19.8)$ \\
\hline \multicolumn{3}{|l|}{ Number of previous pregnancies, $n(\%)$} \\
\hline First & $530(48.4)$ & $668(47.7)$ \\
\hline Second & $565(51.6)$ & $734(52.4)$ \\
\hline \multicolumn{3}{|l|}{ Twin pregnancy, n (\%) } \\
\hline Not twin & $1080(98.5)$ & $1372(97.7)$ \\
\hline Twin & $16(1.5)$ & $32(2.3)$ \\
\hline \multicolumn{3}{|l|}{ Uses fumigation or mosquito coils or net at night, $\mathrm{n}(\%)$} \\
\hline No & $64(5.9)$ & $87(6.3)$ \\
\hline Yes & $1021(94.1)$ & $1304(93.8)$ \\
\hline Mid-upper arm circumference in cm, median (IQR) & $26(24-28)$ & $26(24-28)$ \\
\hline Body mass index $\left(\mathrm{kg} / \mathrm{m}^{2}\right)$, median (IQR) & $22.2(20.2-25.4)$ & $22.6(20.1-25.7)$ \\
\hline \multicolumn{3}{|l|}{ Body mass index $\left(\mathrm{kg} / \mathrm{m}^{2}\right), \mathrm{n}(\%)$} \\
\hline Underweight & $112(10.3)$ & $151(10.8)$ \\
\hline Normal & $681(62.7)$ & $843(60.5)$ \\
\hline Overweight or obese & $293(27.0)$ & $400(28.7)$ \\
\hline Hemoglobin in $\mathrm{g} / \mathrm{dL}$, median (IQR) & $11.6(10.7-12.5)$ & $11.6(10.7-12.4)$ \\
\hline \multicolumn{3}{|l|}{ Anemia status, n (\%) } \\
\hline Not anemic $(\mathrm{Hb} \geq 11.0 \mathrm{~g} / \mathrm{dL})$ & $738(69.9)$ & $938(69.6)$ \\
\hline Anemic $(\mathrm{Hb}<11.0 \mathrm{~g} / \mathrm{dL})$ & $318(30.1)$ & $410(30.4)$ \\
\hline
\end{tabular}


Table 1 The distribution of baseline characteristics among pregnant women with and without placenta sample for placental malaria diagnosis, 2010-2014 Dar-es-Salaam, Tanzania (Continued)

\begin{tabular}{|c|c|c|}
\hline \multirow[t]{2}{*}{ Characteristics } & \multicolumn{2}{|l|}{ Placenta sample } \\
\hline & No $(n=1096)^{a}$ & Yes $(n=1404)$ \\
\hline \multicolumn{3}{|c|}{ Peripheral malaria, n (\%) } \\
\hline Negative & $740(98.0)$ & $1305(98.1)$ \\
\hline Positive & $15(2.0)$ & $26(2.0)$ \\
\hline
\end{tabular}

negative results). Placental malaria was also somewhat more common among women not using mosquito prevention methods such as bed nets, fumigation, and coils (10\% for DNA PCR and 8\% for histopathology versus 6\% for negative results).

Results of the multinomial model for factors associated with placental malaria are summarized in Table 3. Being employed and other forms of employment were associated with reduced odds of HP placental malaria compared to unemployed women $(\mathrm{OR}=0.69$; 95\% CI: $0.47-$ 1.00; $P=0.05$ and OR $=0.49 ; 95 \%$ CI: $0.28-0.86 ; P=0.01$ respectively). Compared to those with a higher education level, pregnant women with the least education (0-7 years of education) had an increased odd of submicroscopic placental malaria $(\mathrm{OR}=2.21$; 95\% CI: 0.994.97; $\mathrm{P}=0.05)$. Similar findings for HP placental malaria infection were observed but estimates were not stable due to the low number of outcomes. Pregnant women who did not use mosquito prevention methods such as fumigation, mosquito coil, or a bed net at night had a $75 \%$ increased risk of sub-microscopic placental malaria $(\mathrm{OR}=1.75 ; 95 \% \mathrm{CI}: 1.05-2.92 ; P=0.03)$.

Being underweight was associated with reduced odds of sub-microscopic placental malaria compared to normal BMI $(\mathrm{OR}=0.33 ; 95 \% \mathrm{CI}: 0.17-0.62 ; P=0.001)$. In contrast, being overweight/obese was associated with increased odds of HP placental malaria $(\mathrm{OR}=1.48 ; 95 \%$ CI: $1.03-2.11 ; \mathrm{P}=0.03)$. Compared to pregnant women who were not anemic in the first trimester, anemic pregnant women had increased odds of sub-microscopic $(\mathrm{OR}=1.59 ; 95 \% \mathrm{CI}: 1.20-2.11 ; \mathrm{P}=0.001)$ and HP placental malaria $(\mathrm{OR}=1.70 ; 95 \% \mathrm{CI}: 1.22-2.38 ; P=0.002)$.

\section{The association between placental malaria and adverse pregnancy outcomes}

The prevalence of LBW was $8 \%$ among HP positive women and 5\% among sub-microscopic positive women (Table 4). LBW was not associated with placental malaria by both diagnostic method. Premature births were common among women with placental malaria by both diagnostic methods (28 and $25 \%$ for HP and sub- microscopic placental malaria respectively). Compared to women negative for placental malaria, women with placental malaria infection had a slightly elevated risk of prematurity, although no statistical evidence for the association $(\mathrm{RR}=1.16 ; \mathrm{CI}: 0.89-1.52 ; P=0.26$ for $\mathrm{HP}$ placental malaria and $\mathrm{RR}=1.14$; CI: $0.90-1.45 ; P=0.27$ for sub-microscopic placental malaria).

A high prevalence of SGA births was found in women with HP placental malaria (23\%), while women with submicroscopic placental malaria had a low prevalence of SGA births (12\%). Compared to women with negative results for both tests, HP placental malaria infection was associated with increased risk of SGA births $(\mathrm{RR}=1.30$; 95\% CI: $0.98-1.72 ; P=0.07$ ), while sub-microscopic infection was associated with reduced risk of SGA births (RR $=0.61 ; 95 \%$ CI: $0.43-0.88 ; P=0.01)$.

\section{Discussion}

The overall prevalence of placental malaria was 8 , and $12 \%$ for HP and sub-microscopic placental malaria respectively. Being underweight was associated with a reduced risk of sub-microscopic placental malaria while being overweight/obese was associated with a higher risk of HP placental malaria infection. Not using antimalarial preventive measures and being anemic were associated with increased risk of sub-microscopic placental malaria. We noted an increased risk of SGA births in women with HP placental malaria and a decreased risk of SGA among women with sub-microscopic placental malaria. There was no statistically significant increased risk of premature births in women with either HP or sub-microscopic placental malaria.

Increased premature births among women infected with placental malaria have been observed in Uganda [30] and Papua New Guinea [31]. The Papua New Guinea [31] study further showed that chronic placental malaria was associated with an increased risk of prematurity. A potential mechanism for the association being the stimulation of early labor by the active immune triggered in malaria-infected placentas [32]. However, in the current study, we found a non-significant increased risk 
Table 2 Distribution of baseline characteristics of pregnant women by placental malaria outcome, 2010-2014, Dar-es-Salaam, Tanzania

\begin{tabular}{|c|c|c|c|c|}
\hline \multirow[t]{2}{*}{ Characteristics } & \multicolumn{3}{|c|}{ Placental test results } & \multirow[t]{2}{*}{ Total } \\
\hline & Negative $^{a}$ & DNA PCR Positive & Histopathology positive & \\
\hline Overall, n (\%) & $886(79.5)$ & $136(12.2)$ & $93(8.3)$ & $1115(100)$ \\
\hline Maternal age in years, median (IQR) & $22(20-25)$ & $22(20-26)$ & $22(20-25)$ & $22(20-25)$ \\
\hline \multicolumn{5}{|l|}{ Maternal age in years, n (\%) } \\
\hline$\leq 24$ & $624(70.6)$ & $91(67.9)$ & $65(69.9)$ & $780(70.2)$ \\
\hline $25-34$ & $249(28.2)$ & $40(29.9)$ & $27(29.0)$ & $316(28.4)$ \\
\hline$\geq 35$ & $11(1.2)$ & $3(2.2)$ & $1(1.1)$ & $15(1.4)$ \\
\hline Gestational age in weeks ${ }^{\mathrm{b}}$, median (IQR) & $10.6(8.4-12.1)$ & $10.1(8.0-12.4)$ & $11.3(8.9-12.6)$ & $10.4(8.3-12.3)$ \\
\hline \multicolumn{5}{|l|}{ Employment, n (\%) } \\
\hline Employed $^{c}$ & $283(32.3)$ & $32(23.7)$ & $25(27.2)$ & $340(30.8)$ \\
\hline Unemployed & $451(51.4)$ & $79(58.5)$ & $60(65.2)$ & $590(53.4)$ \\
\hline Other & $143(16.3)$ & $24(17.8)$ & $7(7.6)$ & $174(15.8)$ \\
\hline \multicolumn{5}{|l|}{ Marital status, n (\%) } \\
\hline Living single $^{d}$ & $92(10.5)$ & $11(8.1)$ & $9(9.7)$ & $112(10.1)$ \\
\hline Married or cohabitating & $787(89.5)$ & $124(91.9)$ & $84(90.3)$ & $995(89.9)$ \\
\hline \multicolumn{5}{|l|}{ Years of education, n (\%) } \\
\hline $0-7$ & $630(71.1)$ & $106(77.9)$ & $71(76.3)$ & $807(72.4)$ \\
\hline $8-11$ & $198(22.4)$ & $25(18.4)$ & $21(22.6)$ & $244(21.9)$ \\
\hline$\geq 12$ & $58(6.5)$ & $5(3.7)$ & $1(1.1)$ & $64(5.7)$ \\
\hline \multicolumn{5}{|l|}{ Wealth quartile, n (\%) } \\
\hline 1 (Lowest) & $227(27.6)$ & $33(25.8)$ & $19(21.8)$ & $279(26.9)$ \\
\hline 2 & $194(23.5)$ & $22(17.2)$ & $24(27.6)$ & $240(23.1)$ \\
\hline 3 & $252(30.6)$ & $43(33.6)$ & $23(26.4)$ & $318(30.6)$ \\
\hline 4 (Highest) & $151(18.3)$ & $30(23.4)$ & $21(24.1)$ & $202(19.4)$ \\
\hline \multicolumn{5}{|l|}{ Number of previous pregnancies, n (\%) } \\
\hline First & $430(48.6)$ & $63(46.3)$ & $44(47.3)$ & $537(48.2)$ \\
\hline Second & $454(51.4)$ & $73(53.7)$ & $49(52.7)$ & $576(51.8)$ \\
\hline \multicolumn{5}{|l|}{ Twin pregnancy, n (\%) } \\
\hline Not twin & $864(97.5)$ & $136(100)$ & $90(96.8)$ & $1090(97.8)$ \\
\hline Twin & $22(2.5)$ & 0 & $3(3.2)$ & $25(2.2)$ \\
\hline \multicolumn{5}{|l|}{ Uses fumigation or mosquito coils or net at night, n (\%) } \\
\hline No & $55(6.3)$ & $13(9.8)$ & $7(7.6)$ & $75(6.8)$ \\
\hline Yes & $824(93.7)$ & $120(90.2)$ & $85(92.4)$ & $1029(93.2)$ \\
\hline Mid-upper arm circumference in cm, median (IQR) & $26.0(24.0-28.0)$ & $26.0(24.5-28.7)$ & $27.0(24.3-28.8)$ & $26.0(24.0-28.0)$ \\
\hline Body mass index $\left(\mathrm{kg} / \mathrm{m}^{2}\right)$, median (IQR) & $22.5(20.1-25.9)$ & $23.5(20.9-25.8)$ & $23.4(20.9-26.7)$ & $22.8(20.3-25.9)$ \\
\hline \multicolumn{5}{|l|}{ Body mass index $\left(\mathrm{kg} / \mathrm{m}^{2}\right), \mathrm{n}(\%)$} \\
\hline Underweight & $106(12.1)$ & $5(3.7)$ & $7(7.5)$ & $118(10.6)$ \\
\hline Normal & $515(58.5)$ & $84(61.8)$ & $55(59.1)$ & $654(59.0)$ \\
\hline Overweight or obese & $259(29.4)$ & $47(34.5)$ & $31(33.3)$ & $337(30.4)$ \\
\hline Hemoglobin in $\mathrm{g} / \mathrm{dL}$, median (IQR) & $11.7(10.8-12.4)$ & $11.4(10.7-12.2)$ & $11.5(10.4-12.5)$ & $11.6(10.8-12.4)$ \\
\hline \multicolumn{5}{|l|}{ Anemia status, n (\%) } \\
\hline Not anemic $(\mathrm{Hb} \geq 11.0 \mathrm{~g} / \mathrm{dL})$ & $612(72.0)$ & $88(66.7)$ & $58(63.7)$ & $758(70.6)$ \\
\hline Anemic $(\mathrm{Hb}<11.0 \mathrm{~g} / \mathrm{dL})$ & $238(28.0)$ & $44(33.3)$ & $33(36.3)$ & $315(29.4)$ \\
\hline
\end{tabular}


Table 2 Distribution of baseline characteristics of pregnant women by placental malaria outcome, 2010-2014, Dar-es-Salaam, Tanzania (Continued)

\begin{tabular}{|c|c|c|c|c|}
\hline \multirow[t]{2}{*}{ Characteristics } & \multicolumn{3}{|c|}{ Placental test results } & \multirow[t]{2}{*}{ Total } \\
\hline & Negative $^{a}$ & DNA PCR Positive & Histopathology positive & \\
\hline \multicolumn{5}{|c|}{ Peripheral malaria, n (\%) } \\
\hline Negative & $832(98.5)$ & $131(100)$ & $79(90.8)$ & $1042(98.0)$ \\
\hline Positive & $13(1.5)$ & 0 & $8(9.2)$ & $21(2.0)$ \\
\hline \multicolumn{5}{|c|}{$\begin{array}{l}\text { a Placental malaria test results negative for both Histopathology and PCR tests } \\
\text { b Gestational age at enrollment based on the date of the last menstrual period } \\
\text { c Employed includes skilled, unskilled, and informal employment } \\
\text { d Living single includes never married, divorced, separated, and widow }\end{array}$} \\
\hline
\end{tabular}

of premature births among women with placental malaria compared to women without the infection. The difference could be partly explained by differences in malaria transmission rates. In general urban areas receive fewer infectious bites per year compared to rural settings [33], and in 2009 the entomological inoculation rate in Dar-es-Salaam was 1.3 infectious bites per person per year [34].

The occurrence of IUGR in pregnant women infected with malaria is related to nutrient supply to the fetus. A study of the histopathology of infected placentas showed that the thickening of the cytotrophoblastic membranes may interfere with the nutrient supply to the fetus, resulting in growth retardation [32]. The association we observed between HP placental malaria and SGA was consistent with studies done in Uganda [30], and Gambia [35], although the latter did not account for potential confounders. A study conducted in the Democratic Republic of Congo showed that IUGR was highly associated with three or more cumulative infections, and there was a 2-8-fold increased risk of IUGR among women with evidence of under-nutrition [36]. However, we could not investigate a similar interaction effect between nutritional status and infection in the current study because few women were classified as underweight.

Our findings that sub-microscopic placental malaria was associated with a reduced risk of SGA birth was similar to results from a study done in Benin [37] despite differences in diagnostic methods and timing. The potential mechanism for this finding is unknown, but we speculate that it may involve the acquisition of antibodies in the placenta that inhibited the binding of $P$. falciparum-infected erythrocytes to the placental receptor chondroitin sulfate A (CSA) [38]. High levels of immunoglobulin G (IgG) against one of the placental isolates were previously found to be associated with increased birth weight among women who experienced at least one episode of malaria during pregnancy [39]. Further, Duffy and Fried [38] found that antibodies to placental parasites were related to decreased placental parasitemia and increased birth weight. Although our study participants included women in their first pregnancy who presumably lack immunity to CSA-binding parasite [40], the relationship may be plausible in the context of chronic or repeated infections in the same pregnancy. Findings from a study done in Kenya, that assessed pregnancy-specific $P$. falciparum immune responses among primiparous women showed low-tomedium pregnancy-associated malaria IgG concentration among women with acute or chronic MiP, which was an indication of the development of the immune response to infection [41]. On other hand, malaria infection during early pregnancy has been linked to SGA births [42]. Sub-microscopic placental malaria infection being interpreted to be a recent infection [16], we also suspect that the infections would have been those that occurred in the weeks preceding birth. Therefore, the association observed could have happened by chance.

Being underweight weakens antibody-mediated antimalarial immunity [3]. This study, however, found that underweight was associated with reduced odds of submicroscopic placental malaria. A possible explanation of this finding could be that pregnant women with macronutrient deficiencies (i.e. energy, fat, and protein) are at increased risk of micronutrient deficiency especially iron deficiency [3]. This was found in a study of Indonesian and Ghanaian pregnant women, in which the risk of anemia during early pregnancy was higher in women with lower levels of BMI during early pregnancy [43]. Being underweight may be associated with a reduced risk of placental malaria because of concurrent iron deficiency during pregnancy, which has been associated with reduced risk of malaria infection even during pregnancy $[3,44,45]$. Others have noted that pregnant women who are underweight during early pregnancy may already have been exposed to malaria infection and acquired pregnancy-specific immunity that protects them from further infection later in the same pregnancy [46].

We also noted the increased odds of HP placental malaria in women classified as overweight/obese. This finding was similar to that of a previous study done in Sweden [47], which found an increased risk of severe 
Table 3 Factors associated with placental malaria among women with sample for both diagnosis, 2010-2014, Dar es Salaam, Tanzania $(n=941)^{\mathrm{a}, \mathrm{b}}$

\begin{tabular}{|c|c|c|c|c|}
\hline \multirow[t]{2}{*}{ Characteristics } & \multicolumn{2}{|c|}{ DNA PCR positive } & \multicolumn{2}{|c|}{ Histopathology positive } \\
\hline & OR [95\% Cl] & $P$-value & OR $[95 \% \mathrm{Cl}]$ & $P$-value \\
\hline \multicolumn{5}{|l|}{ Maternal age in years } \\
\hline$\leq 24$ & Ref & & Ref & \\
\hline$\geq 25$ & $1.20[0.88,1.64]$ & 0.24 & $1.15[0.79,1.68]$ & 0.46 \\
\hline Gestational age in weeks $^{c}$ & $0.97[0.92,1.02]$ & 0.23 & $1.08[1.00,1.15]$ & 0.04 \\
\hline \multicolumn{5}{|l|}{ Employment } \\
\hline Unemployed & Ref & & Ref & \\
\hline Employed $^{d}$ & $0.72[0.52,1.00]$ & 0.05 & $0.69[0.47,1.00]$ & 0.05 \\
\hline Other & $1.08[0.75,1.57]$ & 0.67 & $0.49[0.28,0.86]$ & 0.01 \\
\hline \multicolumn{5}{|l|}{ Years of education } \\
\hline $0-7$ & $2.21[0.99,4.97]$ & 0.05 & $5.87[1.25,27.51]$ & 0.02 \\
\hline $8-11$ & $1.85[0.80,4.27]$ & 0.15 & $6.48[1.37,30.68]$ & 0.02 \\
\hline$\geq 12$ & Ref & & Ref & \\
\hline \multicolumn{5}{|l|}{ Wealth index } \\
\hline 1 (Lowest) & Ref & & Ref & \\
\hline 2 & $0.78[0.52,1.18]$ & 0.24 & $1.58[1.00,2.50]$ & 0.05 \\
\hline 3 & $1.10[0.77,1.57]$ & 0.62 & $0.91[0.571 .46]$ & 0.69 \\
\hline 4 (Highest) & $1.22[0.82,1.82]$ & 0.33 & $1.53[0.94,2.48]$ & 0.09 \\
\hline \multicolumn{5}{|l|}{ Number of previous pregnancies } \\
\hline First & $0.94[0.71,1.25]$ & 0.69 & $1.11[0.79,1.55]$ & 0.56 \\
\hline Second & Ref & & Ref & \\
\hline \multicolumn{5}{|c|}{ Uses fumigation or mosquito coils or net at night } \\
\hline No & $1.75[1.05,2.92]$ & 0.03 & $1.45[0.76,2.74]$ & 0.26 \\
\hline Yes & Ref & & Ref & \\
\hline \multicolumn{5}{|l|}{ Body mass index $\left(\mathrm{kg} / \mathrm{m}^{2}\right)$} \\
\hline Underweight & $0.33[0.17,0.62]$ & 0.001 & $0.78[0.44,1.36]$ & 0.38 \\
\hline Normal & Ref & & Ref & \\
\hline Overweight or obese & $1.21[0.90,1.63]$ & 0.21 & $1.48[1.03,2.11]$ & 0.03 \\
\hline \multicolumn{5}{|l|}{ Anemia status } \\
\hline Not anemic $(\mathrm{Hb} \geq 11.0 \mathrm{~g} / \mathrm{dL})$ & Ref & & Ref & \\
\hline Anemic $(\mathrm{Hb}<11.0 \mathrm{~g} / \mathrm{dL})$ & $1.59[1.20,2.11]$ & 0.001 & $1.70[1.22,2.38]$ & 0.002 \\
\hline
\end{tabular}

\section{$O R$ is an odds ratio}

$\mathrm{Cl}$ is the confidence interval

${ }^{a}$ The model was adjusted for the trial supplement regimen received

b The weighted analysis was used to account for missing placenta samples for placental malaria diagnosis. Multinomial distribution with the nominal outcome, each PCR positive and histopathology positive were compared to negative for both tests

${ }^{c}$ Gestational age at enrollment based on last menstrual period

d Employed includes skilled, unskilled, and informal employment

malaria among obese participants compared to normal weight participants, even though the study focused on the general adult population. Given the increased burden of overweight and obesity among women of reproductive age in urban Africa [48], our findings suggest that malaria control programs should also consider the nutrition status of the targeted population.

Being anemic during the first trimester was associated with an increased risk of sub-microscopic placental malaria, consistent with a study done in Malawi [15], but inconsistent with a study done in Cameroon [49]. Since anemia was detected at recruitment there is a possibility that low hemoglobin levels observed at recruitment resulted from prior malaria infections. Malaria infection detected in the placenta typically first occurred in the periphery many months earlier (possibly in the first trimester) resulting in anemia. Therefore, establishing a temporal pathway for the association observed in 
Table 4 Relationship between low birth weight, premature, and small for gestational age births and placental malaria, 2010-2014, Dar es Salaam, Tanzania ${ }^{a, b}$

\begin{tabular}{|c|c|c|c|c|c|c|}
\hline \multirow[t]{2}{*}{ Exposure of interest } & \multicolumn{2}{|c|}{ Proportion distribution of exposure $n(\%)$} & \multicolumn{2}{|c|}{ Univariable model } & \multicolumn{2}{|c|}{ Multivariable model } \\
\hline & Outcome & No outcome & $\mathrm{RR}[95 \% \mathrm{Cl}]$ & $P$-value & RR $[95 \% \mathrm{Cl}]$ & $P$-value \\
\hline \multicolumn{7}{|l|}{ Low birth weight outcome ${ }^{c}$} \\
\hline Placental malaria & & & $n=922$ & & $n=922$ & \\
\hline Negative & $72(8.7)$ & $756(91.3)$ & Ref & & Ref & \\
\hline DNA PCR positive & $7(5.4)$ & $123(94.6)$ & $0.46[0.25,0.85]$ & 0.01 & $0.58[0.23,1.45]^{d}$ & 0.25 \\
\hline Histopathology positive & $7(7.8)$ & $83(92.2)$ & $0.86[0.50,1.46]$ & 0.57 & $0.90[0.43,1.90]^{\mathrm{d}}$ & 0.79 \\
\hline \multicolumn{7}{|l|}{ Premature births outcome ${ }^{e}$} \\
\hline Placental malaria & & & $n=917$ & & $\mathrm{n}=917$ & \\
\hline Negative & $175(21.2)$ & $651(78.8)$ & Ref & & Ref & \\
\hline DNA PCR positive & $32(24.8)$ & $97(75.2)$ & $1.10[0.87,1.40]$ & 0.42 & $1.14[0.90,1.45]$ & 0.27 \\
\hline Histopathology positive & $24(26.7)$ & $66(73.3)$ & $1.18[0.90,1.53]$ & 0.23 & $1.16[0.89,1.52]$ & 0.26 \\
\hline \multicolumn{7}{|c|}{ Small for gestational age outcome $e^{e}$} \\
\hline Placental malaria & & & $n=892$ & & $n=892$ & \\
\hline Negative & $144(18.0)$ & $656(82.0)$ & Ref & & Ref & \\
\hline DNA PCR positive & $16(12.4)$ & $113(87.6)$ & $0.60[0.42,0.86]$ & 0.01 & $0.61[0.43,0.88]$ & 0.01 \\
\hline Histopathology positive & $20(22.5)$ & $69(77.5)$ & $1.25[0.94,1.65]$ & 0.13 & $1.30[0.98,1.72]$ & 0.07 \\
\hline
\end{tabular}

$R R$ is a relative risk

$\mathrm{Cl}$ is the confidence interval

The negative placental test was referring to negative to both PCR and histopathology tests

a All multivariable models were adjusted for employment, years of education, wealth quartiles, supplements regimen, gravidity, use of combination malaria preventions, twin pregnant status, BMI, and anemia status at baseline

${ }^{\mathrm{b}}$ Weighted models were used to account for missing placenta samples for placental malaria diagnosis

c Low birth weight is defined as live born with a birth weight below $2.5 \mathrm{~kg}$

${ }^{d}$ Multivariate Poisson distribution was applied to estimate relative risk because of the log-binomial model did not converge with desired covariates

e Premature births were defined as live born delivered before 37 weeks of gestation

e Small for gestational age birth was defined as live born infants with a birth weight below 10th percentile for sex and gestational age, based on INTERGROWTH-21st standards

the current study is not possible given the nature of the study.

Intermittent preventive treatment in pregnancy (IPTp) with SP is among the strategies used for preventing adverse pregnancy outcomes associated with MiP in Tanzania [50], and it is available as standard of care for women attending antenatal care clinics. It has been shown that SP-IPTp can treat even sub-microscopic infection, but does not prevent new infections [14]. Hence, other malaria vector control strategies such as mosquito coils [51], fumigation [52], and treated bed nets [52, 53] are also used for malaria control. We found that not using these preventive methods was associated with an increased risk of sub-microscopic placental malaria. These findings support the protective role of alternative malaria control measures [52, 54]. However, others have suggested that mosquito coils have low mosquito repellency ability [51], and their effect on malaria prevention is not well established [55].

To our knowledge, our study is one of the first large studies to investigate the associations of placental malaria and adverse pregnancy outcomes among women in their first and second pregnancy in urban Tanzania.
However, the study has some limitations first, placental malaria was diagnosed at delivery. Establishing the temporal relationship between malaria and baseline characteristics such as maternal anemia and underweight is therefore challenging, especially if malaria infection may have happened before enrolment. However, past infections diagnosed at delivery are informative with respect to the presence of MiP [6]. We also had very few women diagnosed with peripheral malaria at baseline $(n=41)$. DNA PCR diagnosis for placental malaria, though highly sensitive compared to histopathology, may detect both viable, and non-viable or gametocytes [6], which may complicate the interpretation of our results. However, sub-microscopic gametocytes have an important role in malaria transmission and pregnant women have been found to be reservoirs of sub-microscopic gametocytes [12]. It has been suggested that the majority of submicroscopic malaria infection may reflect recent infection based on genotyping findings [16]. Therefore, learning about the relevance of this infection on clinical outcomes is crucial. Also, gestational age was estimated using the last menstrual period. This method is known to be vulnerable to misclassification of prematurity 
compared to ultrasound [56, 57]. However, in Tanzania ultrasound is not routinely available and where available it is not affordable for the majority. Lastly, approximately half of the study participants did not have a placental sample for placental malaria infection. To address potential selection bias due to missing data, we applied a weighted analysis.

In summary, social determinants such as low educational level may influence the understanding and interpretation of anti-malaria messages delivered at antenatal clinics. It is crucial that these programs tailor their messages and campaigns such that even those with low or no education are well informed. Further, even though over $90 \%$ reported the use of at least one malaria preventive measure, more effort should be directed to pregnant women who do not use recommended preventive measures. The integration of nutrition services that target both extremes of the malnutrition spectrum is warranted. Lastly, further research is also needed to understand sub-microscopic placental malaria and the underlying malaria immune response mechanisms that might be linked with the protective effect of SGA births among those infected.

\section{Abbreviations}

HP: Histology-positive; PCR: Polymerase Chain Reaction; SGA: Small-forgestational age; IQR: Interquartile range; RR: Relative risk; Cl: Confidence interval; P.falciparum: Plasmodium falciparum; MiP: Malaria infection during pregnancy; HIV: Human immunodeficiency virus; SP: Sulphadoxinepyrimethamine; LBW: Low birth weight; BMI: Body mass index; RNA: Ribonucleic acid; qRT-PCR: Quantitative real-time polymerase chain reaction; IUGR: Intrauterine growth retardation; IgG: Immunoglobulin G; CSA: Chondroitin sulfate A; IPTp: Intermittent preventive treatment in pregnancy

\section{Acknowledgments}

We would like to thank the study participants and the field teams, including study coordinators, doctors, nurses, midwives, supervisors, and the laboratory, administrative, and data staff at MUHAS and the clinic sites for their contributions to the study. Particular appreciation to the dedication offered by the field team including Vera Juma (deceased), Jeremy Kane, Juliana Mghamba, Fee Msafiri, Mwanaidi Said, and Kristina Lugangira. We also thank Paul Ng'walali and Amos Mwakigonja at MUHAS for their technical assistance in placental histopathology; Jaume Ordi and Atis Muehlenbachs for external review of the placental histopathology; and Michael Waisberg for malarial PCR on representative cases, as well as Manoj Duraisingh and Katy Shaw-Saliba at the Harvard TH Chan School of Public Health, and Ambroise Ahouidi at Le Dantec Hospital, Senegal, for their expertise in tissue homogenization, DNA extraction, and qPCR methods for diagnosing placental malaria. Finally, we thank DSMB members Jeffrey Griffiths, Mohamed Bakari, Henrik Friis, David Wypij, and Hassan Mshinda.

\section{Disclaimer}

"Research reported in this publication was supported by the Fogarty International Center, of the National Institutes of Health under Award Number D43 TW 007886. The content is solely the responsibility of the authors and does not necessarily represent the official views of the National Institutes of Health."

\section{Authors' contributions}

Conceptualization, W.W.F., A.V.K., E.H., A.M.D.; formal analysis, A.V.K.; investigation, A.V.K., A.M.D., F.M.M., A.I.A., S.A., F.O.O., H.M., D.H.H. and W.W.F.; writing -original draft preparation, A.V.K.; writing - review and editing, A.V.K., A.M.D., E.H., F.O.O., H.M., D.H.H., A.I.A., S.A. and W.W.F.; supervision, E.H. and
W.W.F.; funding acquisition, W.W.F. All authors of this manuscript provided technical input and approved the final manuscript submitted to the journal.

\section{Funding}

The current study was possible through the Global Infectious Diseases (GID) training program sponsored by the U.S. National Institute of Health (NIH) Fogarty International Center, grant number D43 TW 007886. The parent trial was supported by a grant from the National Institute of Child Health and Human Development (NICHD RO1 HD057941-01). Both funding institutions had no role in study design, data collection, analysis and interpretation, manuscript writing, and the choice of journal for submission of the manuscript for publication.

\section{Availability of data and materials}

The datasets generated and/or analyzed are not publicly available because they contain sensitive information of participants but are available from the corresponding author on reasonable request.

\section{Ethics approval and consent to participate}

The parent trial obtained ethical approval from the Harvard T.H. Chan School of Public Health Institutional Review Board (the IRB approval code is 18,573), the Muhimbili University of Health and Allied Sciences (MUHAS) Senate of Research and Publication Committee (the MUHAS approval reference is Ref.No.2015-06-26/AECNol.IX/119), and Tanzania's National Institute of Medical Research (NIMRI approval code is NIMR/HQ/R.8a/Nol. IX/966). All study participants were informed about the study and written consent was obtained from participants who accepted to participate in the study before data collection was initiated.

Consent for publication

Not applicable.

\section{Competing interests}

The authors declared that they have no competing interests.

\section{Author details}

${ }^{1}$ Department of Intervention and Clinical Trials, Ifakara Health Institute, P.O. Box 53, Ifakara, Morogoro, Tanzania. ${ }^{2}$ Department of Global Health and Population, Harvard T.H. Chan School of Public Health, Boston, MA, USA. ${ }^{3}$ Departments of Internal Medicine; and Microbiology and Immunology, School of Medicine, Muhimbili University of Health and Allied Sciences, Dar-es-Salaam, Tanzania. ${ }^{4}$ Department of Global Health, Boston University School of Public Health, Boston, MA, USA. ${ }^{5}$ Section of Infectious Diseases, Department of Medicine, Boston University School of Medicine, Boston, MA, USA.

Received: 27 December 2019 Accepted: 16 October 2020

Published online: 27 October 2020

\section{References}

1. Steketee RW, Nahlen BL, Parise ME, Menendez C. The Burden of Malaria in Pregnancy in Malaria-Endemic Areas. American Society of Tropical Medicine and Hygiene; 2001 [cited 2019 Aug 16]. Available from: https://www.ncbi. nlm.nih.gov/books/NBK2623/.

2. Desai M, ter Kuile FO, Nosten F, McGready R, Asamoa K, Brabin B, et al. Epidemiology and burden of malaria in pregnancy. Lancet Infect Dis. 2007; 7(2):93-104 [cited 2019 Aug 16]. Available from: https://linkinghub.elsevier. com/retrieve/pii/S147330990770021X.

3. Unger HW, Ashorn P, Cates JE, Dewey KG, Rogerson SJ. Undernutrition and malaria in pregnancy - a dangerous dyad? BMC Med. 2016;14(1):142 [cited 2019 Aug 16]. Available from: doi: https:/doi.org/10.1186/s12916-016-0695-2.

4. Lohoue J, Leke RFG, Leke R, Tako EA, Zhou A, Taylor DW. RISK FACTORS FOR PLACENTAL MALARIA AND ITS EFFECT ON PREGNANCY OUTCOME IN YAOUNDE, CAMEROON. Am J Trop Med Hygiene . 2005;72(3):236-242 [cited 2019 Aug 16]. Available from: http://www.ajtmh.org/content/journals/10.426 9/ajtmh.2005.72.236

5. Mutabingwa TK, Bolla MC, Li J-L, Domingo GJ, Li X, Fried M, et al. Maternal Malaria and Gravidity Interact to Modify Infant Susceptibility to Malaria. PLoS Medicine. 2005;2(12):e407 [cited 2019 Aug 16]. Available from: doi: https://doi.org/10.1371/journal.pmed.0020407. 
6. Kattenberg JH, Ochodo EA, Boer KR, Schallig HD, Mens PF, Leeflang MM. Systematic review and meta-analysis: rapid diagnostic tests versus placental histology, microscopy and PCR for malaria in pregnant women. Malaria J. 2011;10(1):321 [cited 2019 Aug 16]. Available from. https://doi.org/10.1186/ 1475-2875-10-321.

7. Zhou Z, Mitchell RM, Gutman J, Wiegand RE, Mwandama DA, Mathanga DP, et al. Pooled PCR testing strategy and prevalence estimation of submicroscopic infections using Bayesian latent class models in pregnant women receiving intermittent preventive treatment at Machinga District Hospital, Malawi, 2010. Malaria J. 2014;13(1):509 [cited 2019 Aug 16]. Available from. https://doi.org/10.1186/1475-2875-13-509.

8. Minja DT, Schmiegelow C, Oesterholt M, Magistrado PA, Boström S, John D, et al. Reliability of rapid diagnostic tests in diagnosing pregnancy-associated malaria in north-eastern Tanzania. Malaria J. 2012;11(1):211 [cited 2019 Aug 16]. Available from. https://doi.org/10.1186/1475-2875-11-211.

9. Valente B, Campos PA, do Rosário VE, Varandas L, Silveira H. Prevalence and risk factors of Plasmodium falciparum infections in pregnant women of Luanda, Angola: P. falciparum infections in pregnant women in Luanda. Trop Med Int Health. 2011;16(10):1206-14 [cited 2019 Aug 16]. Available from: http://doi.wiley.com/10.1111/j.1365-3156.2011.02830.x.

10. Mayor A, Serra-Casas E, Bardají A, Sanz S, Puyol L, Cisteró P, et al. Submicroscopic infections and long-term recrudescence of Plasmodium falciparum in Mozambican pregnant women. Malaria J. 2009;8(1):9 [cited 2019 Aug 16]. Available from: doi: https://doi.org/10.1186/1475-2875-8-9.

11. Omer SA, Noureldein AN, Eisa H, Abdelrahim M, Idress HE, Abdelrazig AM, et al. Impact of Submicroscopic Plasmodium falciparum Parasitaemia on Maternal Anaemia and Low Birth Weight in Blue Nile State, Sudan. J Trop Med. 2019;2019:1-7 [cited 2019 Aug 16]. Available from: https://www. hindawi.com/journals/jtm/2019/3162378/.

12. Lamptey H, Ofori MF, Kusi KA, Adu B, Owusu-Yeboa E, Kyei-Baafour E, et al. The prevalence of submicroscopic Plasmodium falciparum gametocyte carriage and multiplicity of infection in children, pregnant women and adults in a low malaria transmission area in Southern Ghana. Malaria J. 2018; 17(1):331 [cited 2019 Aug 16]. Available from. https://doi.org/10.1186/ s12936-018-2479-y.

13. Bhatt S, Weiss DJ, Cameron E, Bisanzio D, Mappin B, Dalrymple U, et al. The effect of malaria control on Plasmodium falciparum in Africa between 2000 and 2015. Nature. 2015 Oct 8;526(7572):207-11.

14. Cohee LM, Kalilani-Phiri L, Boudova S, Joshi S, Mukadam R, Seydel KB, et al. Submicroscopic malaria infection during pregnancy and the impact of intermittent preventive treatment. Malaria J. 2014;13(1):274 [cited 2019 Aug 16]. Available from. https://doi.org/10.1186/1475-2875-13-274.

15. Kalilani-Phiri L, Thesing PC, Nyirenda OM, Mawindo P, Madanitsa M, Membe $G$, et al. Timing of Malaria Infection during Pregnancy Has Characteristic Maternal, Infant and Placental Outcomes. PLOS ONE. 2013;8(9):e74643 [cited 2019 Aug 16]. Available from: https://journals.plos.org/plosone/article?id= 10.1371/journal.pone.0074643.

16. Cottrell G, Moussiliou A, Luty AJF, Cot M, Fievet N, Massougbodji A, et al. Submicroscopic Plasmodium falciparum Infections Are Associated With Maternal Anemia, Premature Births, and Low Birth Weight. Clin Infect Dis. 2015;60(10):1481-1488 [cited 2019 Aug 16]. Available from: https:// academic.oup.com/cid/article/60/10/1481/338982.

17. Adegnika AA, Verweij JJ, Agnandji ST, Chai SK, Breitling LP, Ramharter M, et al. Microscopic and sub-microscopic Plasmodium falciparum infection, but not inflammation caused by infection, is associated with low birth weight. Am J Trop Med Hyg. 2006;75(5):798-803.

18. mpac-sept2015-erg-mip-report.pdf [Internet]. [cited 2020 May 3]. Available from: https://www.who.int/malaria/mpac/mpac-sept2015-erg-mip-report.pdf.

19. Darling AM, Mugusi FM, Etheredge AJ, Gunaratna NS, Abioye Al, Aboud S, et al. Vitamin A and Zinc Supplementation among Pregnant Women to Prevent Placental Malaria: A Randomized, Double-Blind, PlaceboControlled Trial in Tanzania. Am J Trop Med Hygiene. 2017:16-0599 [cited 2019 Aug 16]. Available from: http://www.ajtmh.org/lookup/doi/1 0.4269/ajtmh.16-0599.

20. Filmer D, Pritchett LH. Estimating Wealth Effects without Expenditure Dataor Tears: An Application to Educational Enrollments in States of India. Demography. 2001;38(1):115-32 [cited 2019 Aug 16]. Available from: https://www.jstor.org/stable/3088292.

21. Body mass index - BMI [Internet]. 2019 [cited 2019 Dec 27]. Available from: http://www.euro.who.int/en/health-topics/disease-prevention/nutrition/ahealthy-lifestyle/body-mass-index-bmi.
22. WHO_NMH_NHD_MNM_11.1_eng.pdf [Internet]. [cited 2019 Dec 27]. Available from: https://apps.who.int/iris/bitstream/handle/10665/85839/ WHO_NMH_NHD_MNM_11.1_eng.pdf?sequence=22\&isAllowed=y.

23. Rosanas-Urgell A, Mueller D, Betuela I, Barnadas C, Iga J, Zimmerman PA, et al. Comparison of diagnostic methods for the detection and quantification of the four sympatric Plasmodium species in field samples from Papua New Guinea. Malaria J. 2010;9(1):361 [cited 2019 Aug 16]. Available from. https://doi.org/10.1186/1475-2875-9-361.

24. Kamau E, Tolbert LS, Kortepeter L, Pratt M, Nyakoe N, Muringo L, et al. Development of a Highly Sensitive Genus-Specific Quantitative Reverse Transcriptase Real-Time PCR Assay for Detection and Quantitation of Plasmodium by Amplifying RNA and DNA of the 18S rRNA Genes. J Clin Microbiol. 2011;49(8):2946-53 [cited 2019 Aug 16]. Available from: https:// jcm.asm.org/content/49/8/2946.

25. Villar J, Cheikh Ismail L, Victora CG, Ohuma EO, Bertino E, Altman DG, et al. International standards for newborn weight, length, and head circumference by gestational age and sex: the newborn cross-sectional study of the INTERGROWTH-21st project. Lancet. 2014;384(9946):857-68.

26. Villar J, Giuliani F, Fenton TR, Ohuma EO, Ismail LC, Kennedy SH, et al. INTE RGROWTH-21st very preterm size at birth reference charts. Lancet. 2016; 387(10021):844-5.

27. Seaman SR, White IR. Review of inverse probability weighting for dealing with missing data. Stat Methods Med Res. 2013;22(3):278-95 [cited 2019 Aug 16]. Available from. https://doi.org/10.1177/0962280210395740.

28. Spiegelman D, Hertzmark E. Easy SAS Calculations for Risk or Prevalence Ratios and Differences. Am J Epidemiol. 2005;162(3):199-200 [cited 2019 Aug 16]. Available from: https://academic.oup.com/aje/article/162/3/199/171116.

29. Firth D. Bias Reduction of Maximum Likelihood Estimates. Biometrika. 1993; 80(1):27-38 [cited 2019 May 6]. Available from: https://www.jstor.org/ stable/2336755

30. Kapisi J, Kakuru A, Jagannathan P, Muhindo MK, Natureeba P, Awori P, et al. Relationships between infection with Plasmodium falciparum during pregnancy, measures of placental malaria, and adverse birth outcomes. Malar J. 2017;16(1):400.

31. Lufele E, Umbers A, Ordi J, Ome-Kaius M, Wangnapi R, Unger $H$, et al. Risk factors and pregnancy outcomes associated with placental malaria in a prospective cohort of Papua New Guinean women. Malar J. 2017;16(1):427.

32. Uneke CJ. Impact of placental Plasmodium falciparum malaria on pregnancy and perinatal outcome in sub-Saharan Africa: II: effects of placental malaria on perinatal outcome; malaria and HIV. Yale J Biol Med. 2007;80(3):95-103.

33. Robert V, Macintyre K, Keating J, Trape J-F, Duchemin J-B, Warren M, et al. MALARIA TRANSMISSION IN URBAN SUB-SAHARAN AFRICA. Am J Trop Med Hygiene. 2003;68(2):169-76.

34. Geissbühler Y, Kannady K, Chaki PP, Emidi B, Govella NJ, Mayagaya V, et al. Microbial larvicide application by a large-scale, community-based program reduces malaria infection prevalence in urban Dar Es Salaam, Tanzania. PLoS ONE. 2009;4(3):e5107.

35. Okoko BJ, Ota MO, Yamuah LK, Idiong D, Mkpanam SN, Avieka A, et al. Influence of placental malaria infection on foetal outcome in the Gambia: twenty years after lan Mcgregor. J Health Popul Nutr. 2002;20(1):4-11.

36. Landis SH, Lokomba V, Ananth CV, Atibu J, Ryder RW, Hartmann KE, et al. Impact of maternal malaria and under-nutrition on intrauterine growth restriction: a prospective ultrasound study in Democratic Republic of Congo. Epidemiol Infect. 2009 Feb;137(2):294-304.

37. Accrombessi M, Yovo E, Fievet N, Cottrell G, Agbota G, Gartner A, et al. Effects of Malaria in the First Trimester of Pregnancy on Poor Maternal and Birth Outcomes in Benin. Clin Infect Dis. 2018.

38. Duffy PE, Fried M. Antibodies That Inhibit Plasmodium falciparum Adhesion to Chondroitin Sulfate A Are Associated with Increased Birth Weight and the Gestational Age of Newborns. Infect Immun. 2003;71(11):6620-3 [cited 2019 Aug 16]. Available from: https://www.ncbi.nlm.nih.gov/pmc/articles/ PMC219546/.

39. Mayor A, Kumar U, Bardají A, Gupta P, Jiménez A, Hamad A, et al. Improved pregnancy outcomes in women exposed to malaria with high antibody levels against Plasmodium falciparum. J Infect Dis. 2013;207(11):1664-74.

40. Fried M, Duffy PE. Malaria during Pregnancy. Cold Spring Harb Perspect Med. 2017;7(6) [cited 2019 Aug 16]. Available from: https://www.ncbi.nlm. nih.gov/pmc/articles/PMC5453384/.

41. Staalsoe T, Shulman CE, Bulmer JN, Kawuondo K, Marsh K, Hviid L. Variant surface antigen-specific lgG and protection against clinical consequences of 
pregnancy-associated Plasmodium falciparum malaria. Lancet. 2004; 363(9405) [cited 2019 Aug 16]. Available from: https://ora.ox.ac.uk/objects/ uuid:172544d7-2e73-4c9f-8d5d-213e91e5d04a.

42. Umbers AJ, Aitken EH, Rogerson SJ. Malaria in pregnancy: small babies, big problem. Trends Parasitol. 2011 Apr;27(4):168-75.

43. Mocking M, Savitri Al, Uiterwaal CSPM, Amelia D, Antwi E, Baharuddin M, et al. Does body mass index early in pregnancy influence the risk of maternal anaemia? An observational study in Indonesian and Ghanaian women. BMC Public Health. 2018;18(1):873 [cited 2019 Aug 16]. Available from. https://doi.org/10.1186/s12889-018-5704-2.

44. Moya-Alvarez V, Cottrell G, Ouédraogo S, Accrombessi M, Massougbodgi A, Cot M. Does Iron Increase the Risk of Malaria in Pregnancy? Open Forum Infect Dis. 2015;2(2) [cited 2019 Aug 16]. Available from: https://www.ncbi. nlm.nih.gov/pmc/articles/PMC4567087/.

45. Kabyemela ER, Fried M, Kurtis JD, Mutabingwa TK, Duffy PE. Decreased susceptibility to Plasmodium falciparum infection in pregnant women with iron deficiency. J Infect Dis. 2008 Jul 15;198(2):163-6.

46. Chandrasiri UP, Fowkes FJ, Richards JS, Langer C, Fan Y-M, Taylor SM, et al. The impact of lipid-based nutrient supplementation on anti-malarial antibodies in pregnant women in a randomized controlled trial. Malaria J. 2015;14(1):193 [cited 2019 Aug 16]. Available from. https://doi.org/10.1186/ s12936-015-0707-2.

47. Wyss K, Wångdahl A, Vesterlund M, Hammar U, Dashti S, Naucler P, et al. Obesity and diabetes as risk factors for severe Plasmodium falciparum Malaria: results from a Swedish Nationwide study. Clin Infect Dis. 2017 Sep 15:65(6):949-58

48. Amugsi DA, Dimbuene ZT, Mberu B, Muthuri S, Ezeh AC. Prevalence and time trends in overweight and obesity among urban women: an analysis of demographic and health surveys data from 24 African countries, 1991-2014. BMJ Open. 2017 Oct 27;7(10):e017344.

49. Walker-Abbey A, Djokam RRT, Eno A, Leke RFG, Titanji VPK, Fogako J, et al. Malaria in pregnant Cameroonian women: the effect of age and gravidity on submicroscopic and mixed-species infections and multiple parasite genotypes. Am J Trop Med Hyg. 2005;72(3):229-35.

50. Mubyazi G, Bloch P, Kamugisha M, Kitua A, ljumba J. Intermittent preventive treatment of malaria during pregnancy: a qualitative study of knowledge, attitudes and practices of district health managers, antenatal care staff and pregnant women in Korogwe District, North-Eastern Tanzania. Malaria J. 2005:4(1):31 [cited 2019 Aug 16]. Available from. https://doi.org/10.1186/ 1475-2875-4-31.

51. Hogarh JN, Agyekum TP, Bempah CK, Owusu-Ansah EDJ, Avicor SW, Awandare GA, et al. Environmental health risks and benefits of the use of mosquito coils as malaria prevention and control strategy. Malaria J. 2018; 17(1):265 [cited 2019 Aug 16]. Available from: doi: https://doi.org/10.1186/ s12936-018-2412-4.

52. Choi L, Richardson M, Malone D, Pryce J. Insecticide space spraying for preventing malaria transmission. Cochrane Database Syst Rev. 2018;2018(11) [cited 2019 Aug 16]. Available from: https://www.ncbi.n/m.nih.gov/pmc/ articles/PMC6516806/.

53. Escamilla V, Alker A, Dandalo L, Juliano JJ, Miller WC, Kamthuza $P$, et al. Effects of community-level bed net coverage on malaria morbidity in Lilongwe, Malawi. Malaria J [Internet]. 2017;16(1):142 [cited 2019 Aug 16]. Available from: doi: https://doi.org/10.1186/s12936-017-1767-2.

54. Atieli HE, Zhou G, Afrane Y, Lee M-C, Mwanzo I, Githeko AK, et al. Insecticide-treated net (ITN) ownership, usage, and malaria transmission in the highlands of western Kenya. Parasit Vectors. 2011 Jun 18:4:113.

55. Lawrance CE, Croft AM. Do Mosquito Coils Prevent Malaria? A Systematic Review of Trials. J Travel Med. 2004;11(2):92-96 [cited 2019 Aug 16]. Available from: https://academic.oup.com/jtm/article/11/2/92/1803449.

56. Weinstein JR, Thompson LM, Díaz Artiga A, Bryan JP, Arriaga WE, Omer SB, et al. Determining gestational age and preterm birth in rural Guatemala: a comparison of methods. PLoS One. 2018;13(3):e0193666.

57. Katz J, Wu LA, Mullany LC, Coles CL, Lee ACC, Kozuki N, et al. Prevalence of small-for-gestational-age and its mortality risk varies by choice of birthweight-for-gestation reference population. PLoS One. 2014;9(3):e92074.

\section{Publisher's Note}

Springer Nature remains neutral with regard to jurisdictional claims in published maps and institutional affiliations.

\section{Ready to submit your research? Choose BMC and benefit from:}

- fast, convenient online submission

- thorough peer review by experienced researchers in your field

- rapid publication on acceptance

- support for research data, including large and complex data types

- gold Open Access which fosters wider collaboration and increased citations

- maximum visibility for your research: over $100 \mathrm{M}$ website views per year

At BMC, research is always in progress.

Learn more biomedcentral.com/submissions 